\title{
Türk Hukuk Kütüphanecileri Platformu'nun Oluşum Süreci
}

The Establishment Process of Turkish Platform of Law Librarians

\section{Sami ÇUKADAR*}

\begin{abstract}
Öz
Bilgi ve iletişim teknolojilerindeki gelişmeler toplumları ve bireyleri giderek birbirlerine yakınlaştırmaktadır. Bu nedenle, bilgi ve iletişim teknolojilerini etkin olarak kullanan, bilgiye dayalı karar alma süreçleriyle daha fazla değer üreten bireylerin yetiştirilmesi ve bu gelişime katkıda bulunacak mesleki örgütlerin kurulması son derece önemlidir. Bu bağlamda, kütüphanecilik alanında da sivil toplum kuruluşlarının - derneklerin, konsorsiyumların, platformların ve mesleki birlikteliklerin - kurulması ve desteklenmesi gerekmektedir. Bu çalışmada, Türkiye'de kütüphanecilik alanında faaliyet gösteren sivil toplum kuruluşlarına kısaca değinilmiş ve Türk Hukuk Kütüphanecileri Platformunun oluşum süreci ve faaliyetleri anlatılmıştır. Ayrıca derneklerin meslekler üzerindeki etkileri ve gerekliliği konusunda da görüşler sunulmuştur.
\end{abstract}

Anahtar sözcükler: Hukuk kütüphaneleri, Kütüphanecilik, Dernekler, Türkiye

\section{Abstract}

Developments in information and communication technologies are increasingly causing a convergence of communities and their individuals. It is therefore of vital importance that professional associations take actions in order to take advantage of these developments by helping their members to increase their professional

Md. Yrd.; İstanbul Bilgi Üniversitesi Kütüphanesi, Kurtuluş Deresi Cad. No:47 Dolapdere Beyoğlu / Istanbul (samic@bilgi.edu.tr). 
skills in using information and communication technologies more effectively and hence create more valued added through use of information-based decision processes. Within this context, the establishment and promotion of associations, platforms, consortiums and occupational collaborations have become evermore necessary. In this study, we explain the establishment process and the activities of the Turkish Law Librarians' Platform. Following a brief mention of some other nongovernmental organizations that operate in this discipline, we provide our views on the rationale for and the influence of professional associations.

Keywords: Law libraries, Librarianship, Associations, Turkey

\section{Giriş}

Bilgi ve iletişim teknolojilerindeki gelişmeler küreselleşmeye hız vermektedir. Bu süreçte ortaya çıkan sorunların çözülmesinde, eşitsizliklerin giderilmesinde sivil toplum kuruluşlarına gereksinim vardır. Sivil toplum kuruluşu "resmi kurumlar dışında ve bunlardan bağımsız olarak çalışan politik, sosyal, kültürel, hukuki ve çevresel amaçları doğrultusunda lobi çalışmaları, ikna ve eylemlerle çalışan, üyelerini ve çalışanlarını gönüllülük usulüyle alan, kâr amacı gütmeyen ve gelirlerini bağışlar ve/veya üyelik ödemeleri ile sağlayan kuruluşlar" (Sivil, 2008) olarak tanımlanmaktadır. Genel olarak oda, sendika, vakıf, dernek ve meslek kuruluşları sivil toplum kuruluşları olarak adlandırılır.

\section{Hukuk Kütüphaneciliği Alanında Sivil Toplum Kuruluşları}

Hukuk alanındaki en eski derneklerden biri 1834 yılında Amerika Birleşik Devletleri'nde kurulan Cincinnati Hukuk Kütüphanesi Derneğidir (Kallendorf, 2008). Amerika Hukuk Kütüphaneleri Derneği ise 1906 yılında kurulmuştur ve günümüzde 5000'in üzerinde üyesi bulunmaktadır (About AALL, 2008). Avustralya Hukuk Kütüphanecileri Derneği 1969 yılında altı hukuk kütüphanecisinin girişimiyle oluşturulmuş, halen Avustralya'nın tüm bölgelerinden ve eyaletlerinden 700 üyeye sahip ulusal bir dernek olarak faaliyetlerine devam etmektedir (About us, 2008). İngiltere-İlanda Hukuk Kütüphanecileri Derneğinin kuruluş tarihi de 1969 yılıdır ve günümüzde 900'ün üzerinde üyesi vardır (About BIALL, 2008). 
Ülkemizde ise hukuk kütüphanecileri alanındaki resmi örgütlenme çalışmaları 2006 yılında başlamıştır.

Türkiye'de kütüphanecilik alanındaki dernekler, çalışma grupları, konsorsiyumlar, mesleki birliktelikler son yıllarda önemli gelişmeler göstermektedir. Bu gelişmeler hukuk alanında da bir sivil toplum örgütü veya birlikteliği kurulması konusunda meslektaşları cesaretlendirmiştir.

Türkiye'de İstanbul Bilgi Üniversitesi Kütüphanesi öncülüğünde, hukuk fakültesi olan üniversiteler ile baro ve avukatlık bürosu kütüphanesinde çalışan kütüphaneciler 2007 yılında bir araya gelerek Üniversite ve Araştırma Kütüphanecileri Derneği (ÜNAK) çatısı altında Türk Hukuk Kütüphanecileri Platformunu oluşturmuşlardır. Türk Hukuk Kütüphanecileri Platformunun oluşum sürecine geçmeden önce Türkiye'de kütüphanecilik alanındaki örgütlerden kısaca bahsetmek gerekmektedir.

\section{Türk Kütüphaneciler Derneği}

Türkiye'de kütüphanecilik alanında ilk dernek 19 Kasım 1949 tarihinde Adnan Ötüken öncülüğünde kurulan Türk Kütüphaneciler Derneğidir. Derneğin kuruluş amacı, Türk kütüphanecilerini bir meslek örgütünün çatısı altında toplamak, seslerini duyurabilecekleri, sorunlarını tartışabilecekleri, onlara çözüm yolları arayabilecekleri, dostluk ve dayanışma topluluğu oluşturacakları bir ortam yaratmak olarak belirlenmiştir. Derneğin vizyonu; kütüphanecilik, arşivcilik, belge ve bilgi hizmetleri alanlarında katılıma, paylaşıma ve takım çalışmasına dayalı bir anlayışla kütüphanecilik dünyasına öncülük etmek olarak belirlenmiştir. Misyonu ise:

- Kütüphanecilik, bilgi bilim ve arşivcilik alanlarında bilimselmesleki çalışmalar ve yayımlar yaparak bunları toplumun tüm kesimlerine duyurmak,

- $\quad$ Çok disiplinli hale gelen bilgi ve belge hizmetlerinin önemini topluma benimsetmek,

- Meslek ile ilgili gelişmeleri yakından takip ederek meslek elemanlarını ve toplumu gelişmelerden haberdar etmek / bilgilendirmek, 
- Meslektaşlar arasında dayanışma ve uyumu sağlamak,

- Mesleki ahlak ilkelerinin uygulanmasını sağlamak,

- Kütüphanecilik ve ilgili alanlardaki ulusal ve uluslararası kuruluşlarla iş birliği içine girerek çalışmalarımızı dünya geneline yaymak,

- Bilgi merkezlerini ilgilendiren sorunların çözülmesinde öncülük etmektir.

Türk Kütüphaneciler Derneği bünyesinde mesleğimizin daha etkin ve yaygın olarak gerçekleştirilmesi amacıyla halkla ilişkiler, bilişim, sosyal ve kültürel etkinlikler, düşünce özgürlüğü, Milli Kütüphane adıyla beş adet çalışma grubu bulunmaktadır.

Türk Kütüphaneciler Derneği kuruluşuyla birlikte yayıncılık faaliyetlerine başlamış ve bugüne kadar 150'nin üzerinde kitap yayımlamıştır. 1952 yılında Türk Kütüphaneciler Derneği Bülteni adıyla bir süreli yayın çıkarılmıştır. 1987 yılında başlığı Türk Kütüphaneciliği olarak değiştirilen dergi hakemli ve yılda 4 sayı olarak yayına devam etmektedir. Ayrıca derneğin 25 ayrı ilde şubesi bulunmaktadır (Türk Kütüphaneciler Derneği-TKD, 2008).

\section{Üniversite ve Araştırma Kütüphanecileri Derneği (ÜNAK)}

Kütüphanecilik alanındaki önemli derneklerden biri de 1991 yılında kurulan Üniversite ve Araştırma Kütüphanecileri Derneğidir. Derneğin amacl: "üniversite ve araştırma kütüphanelerinin, dokümantasyon ve enformasyon merkezlerinin ve özel kütüphanelerin, günümüzde hızla değişen ve gelişen teknolojiye bağlı olarak ortaya çıkan sorunlarını incelemek; diğer ülkelerdeki benzer sorun ve çözümlerle karşılaştırmalar yapmak; bu bilgi merkezlerinde çalışan personelin çeşitli sorunlarını irdelemek ve çözüm aramak; yeni teknolojinin uygulanması konusunda faaliyetlerde bulunmak; kısaca bu bilgi merkezlerinin çağdaş kütüphanecilik anlayışına ve işlevlerine uygun olabilmesi için gereğini yapmak" olarak belirtilmektedir.

Üniversite ve Araştırma Kütüphanecileri Derneği bünyesinde OCLC Yürütme Grubu, Web ve Teknik Grup, Sosyal Etkinlikler Grubu, Basın ve Halkla Illişkiler Grubu, Mesleki Etkinlikler Grubu, Tıp 
ve Sağlık Bilimleri Çalışma Grubu ve Türk Hukuk Kütüphanecileri Platformu adıyla altı adet çalışma grubu bulunmaktadır.

ÜNAK, yılda iki defa Bilgi Dünyası adlı hakemli bir dergi ile iki ayda bir elektronik ortamda yayımlanan ÜNAK Haber Bülteni adlı yayınları çıkarmaktadır. Ayrıca ÜNAK bugüne kadar 7 adet kitap yayımlamıştır (Üniversite ve Araştırma Kütüphanecileri DerneğiÜNAK, 2008).

\section{Anadolu Üniversite Kütüphaneleri Konsorsiyumu (ANKOS)}

Türkiye'de kütüphanecilerin oluşturduğu önemli oluşumlardan biri de Anadolu Üniversite Kütüphaneleri Konsorsiyumudur ve 2000 yılında 12 kurumun bir araya gelmesiyle kurulmuştur. 2008 yılı itibarı ile 87 kurum ANKOS'un üyesidir (ANKOS, 2008).

ANKOS'un amacl; üniversite ve araştırma kütüphanelerinin en uygun fiyatla, en fazla elektronik kaynağa erişimlerini sağlamak; ölçek ekonomisi çerçevesinde elektronik ürünlere yapılan yatırımı paylaşmak; Türkiye'deki akademisyen ve öğrencilerin küresel bilgi ağına en üst düzeyde erişimlerini gerçekleştirmek ve eğitim ve araştırmaya kütüphanelerin desteğini arttırmak için ortak çalışmalar yürütmek olarak belirtilmektedir. ANKOS kapsamında çeşitli araştırma ve çalışma grupları bulunmaktadır. Çalışma grupları Lisans Anlaşmaları, Kullanıcı / Kütüphaneci Eğitimi, Kullanıcı İstatistikleri, Açık Erişim ve Kurumsal Arşivler, Tanıtım ve Organizasyon Grubudur. Araştırma grupları ise Elektronik Kitap, Ortak Arayüz, Kampus Dışı Erişim, İşbirliği Araştırma Grubudur*.

Yayın olarak ANKOS yılda bir defa ANKOS e-Bülten'i çıkarmaktadırlar.

\section{Yaratıcı Kütüphane Girişimleri Tanıtım Grubu (ILIPG)}

Kütüphanecilik alanında diğer bir oluşum ise 2002 yılında İstanbul'da bulunan bir grup kütüphaneci tarafından kurulan Yaratıcı Kütüphane Girişimleri Tanıtım Grubu (2008)'dur. Grubunun amacı:

- Türkiye'de halk kütüphaneleri standartlarını geliştirmeye hız vermek,

* http://www.ankos.gen.tr 
- $\quad$ Türkiye'de ve uluslararası düzeyde, kütüphaneci ağlarını ve küresel ağı aktif hale getirmek ve/veya geliştirmek

- Türkiye'de kütüphaneler için lobi faaliyetlerini harekete geçirmek,

- Kütüphanecilerin ve kütüphanecilik öğrencilerinin mesleki ve teknik becerilerini geliştirmek olarak belirtilmektedir.

Grup çalışmalarını kütüphanecilik alanında düzenlediği çeşitli ulusal-uluslararası konferans, toplantı, çalıştay ve projeler ile devam ettirmektedir.

\section{Okul Kütüphanecileri İstanbul Grubu (OKIG)}

Okul Kütüphanecileri İstanbul Grubu-OKiG, ülkemizde okul kütüphaneciliğinin ve bu konudaki bilincin geliştirilmesi gerektiğine inanan bir grup okul kütüphanecisi tarafından 22 Haziran 2002 tarihinde İstanbul'da kurulmuştur. OKiG, yeni bir mesleki oluşumun ve bir sivil toplum uygulaması olmasının yanı sıra, meslektaşlarımızın kendi mesleklerini sahiplenmesini de ifade etmektedir.

Okul Kütüphanecileri İstanbul Grubunun amaçları: Okul kütüphaneciliği alanına yönelik olarak; mesleki iletişimi geliştirmek, yaşanan sorunları tespit etmek ve çözüm yollarını araştırmak, yeni uygulamaların paylaşımını sağlamak suretiyle bir işbirliği kültürünün oluşumuna katkıda bulunmayı amaçlamıştır. Türkiye'de farklı bölgeler ve yapılardaki okullar ve ilgili kurumlara yönelik işbirliği çalışmaları geliştirmek ve ülke genelinde konuyla ilgili duyarlıığın ve bilinçlenmenin gelişmesine katkıda bulunmak da grup amaçları arasında yer almaktadır. Söz konusu amaçlara yönelik olarak; mesleki toplantı ve etkinlikler düzenleme, Milli Eğitim Bakanlığı, üniversiteler, sivil toplum örgütleri, medya kuruşları vb. kurumlarla çeşitli düzeyde ve içerikte işbirliği çalışmaları organize etme, okullarda görevli meslektaşlarımızın ihtiyaç duyduğu paylaşımlarda bulunma ve gerekli ortamları sağlama gibi aktivitelerin yaşama geçirilmesi amaçlanmıştır (Torun ve Özyurt, 2003).

Okul Kütüphanecileri İstanbul Grubu yaptıkları toplantı, seminer ve diğer etkinliklerle çalışmalarına devam etmektedir. Okul 
Kütüphanecileri İstanbul Grubunun kendi aralarında haberleştikleri bir tartışma listesi ${ }^{*}$ de bulunmaktadır.

\section{Hukuk Kütüphaneleri / Hukuk Kaynakları}

Kütüphaneler var oldukları günden bu yana her türlü bilgi kaynağını her türlü formatta sağlayan, düzenleyen ve kullanıcılarına sunan kurumlardır. Tarihsel süreç içinde bilgi kaynakları artmış, matbaanın icadı, internetteki gelişmeler ile de bilgi hızla çoğalmıştır. Buna bağlı olarak da bilim disiplinlere ayrımış, uzmanlaşma daha önemli hale gelmiştir. Kütüphaneler de bu gelişmelere paralel kendini yenilemiş, tıp kütüphanesi, hukuk kütüphanesi, özel konu kütüphanesi gibi kütüphane türleri ortaya çıkmıştır.

Dünyada hukuk kütüphanelerinin oluşumu 1800 'lü yıllara kadar dayanmaktadır. 1832 yılında Amerika Birleşik Devletleri'nde, Kongre Kütüphanesinin bir kolu olarak kurulan Hukuk Kütüphanesinin koleksiyonu günümüzde 3 milyon kaynağa ulaşmıştır (About the Law, 2008). 1802 yılında ise Jenkins Hukuk Kütüphanesi bilgi kaynakları ile hukuk alanındaki araştırmacıları bir araya getirmek amacıyla kurulmuştur. Kütüphane kitap, e-kitap, dergi, e-dergi, hukuk kaynakları ile hizmetlerine devam etmektedir (About Jenkins, 1996).

Türkiye'de hukuk kütüphanesi adıyla ayrı bir kütüphane türü yapılandııımamıştır. Üniversitelerde merkez kütüphaneye bağlı fakülte kütüphanesi ya da kütüphane içinde ayrılmış özel hukuk koleksiyonları bulunmaktadır. Sayıştay, barolar, araştırma merkezleri gibi yerlerde ise ağırlıklı olarak hukuk kaynaklarından oluşan kütüphaneler vardır ve genellikle kurum ya da kişi adıyla anılmaktadır. $\mathrm{Bu}$ merkezler doğrudan hukuk kütüphanesi olarak anılmasalar da aslında bu ve benzeri yerlerde yapılan işler hukuk kütüphaneciliği ile örtüşmektedir. Çalışanlar açısından ise Türkiye'de bazı kurumlar hukuk kütüphanecisi, hukuk koleksiyonundan sorumlu kütüphaneci gibi ünvanları kullanmaktadır.

Hukuk alanındaki bilgi kaynakları diğer sosyal bilim alanlarındaki bilgi kaynaklarına göre daha hızı değişmektedir. Bu nedenle hukuk koleksiyonundaki kaynakların güncel tutulması

" http://groups.yahoo.com/group/okul_kutuphanecileri/ 
oldukça önemlidir. Kütüphaneler, koleksiyonunda bulunan kanun, devlet teşkilatı rehberi gibi kaynakları sürekli yenilemeli, eğer yenilenemiyorsa bir şekilde bu kaynakların güncellenmediğini kullanıcılarına bildirmekle yükümlüdür.

Hukuk, adalete yönelmiş toplumsal yaşam düzeni olduğu için farklı ülkelerin hukuk sistemlerinden etkilenmektedir. Örneğin Türk Hukuk Sistemi, Ceza Kanunu'nda Italya'dan; Medeni Kanun ve Borçlar Kanunu'nda İsviçre'den, Ceza Muhakemeleri Usulü Kanunu'nda Almanya'dan, İdare Hukuku ve İdari Usul'de ise Fransa'dan etkilenmiştir (Diplock, 1980). Deniz Ticareti ve Sigorta Hukuku'nda Alman hukuk sisteminden ve milletlerarası hukuk bağlamında da İngiltere hukuk sisteminden etkilenmiştir. Dolayısıyla kütüphane koleksiyonlarında bulunan basılı ya da elektronik ortamdaki bilgi kaynakları Türkçe, İngilizce, İtalyanca, Almanca, Fransızca gibi farklı dillerdedir. Bu kaynakların sağlanması, kataloglanması, kullanıma sunulması ve danışma hizmetlerinin verilmesi farklı özellikler gerektirmektedir.

Gerek bilgi kaynaklarının özelliği, gerekse bilgi hizmetlerinin sunulma özelliği ve diğer nedenlerden dolayı dünyada hukuk kütüphaneciliği ayrı ve özel bir tür olarak yerini almıştır. Dünyada ilk hukuk kütüphanesi 1802 yılında kurulmuş, Hukuk Kütüphanecileri Derneği ise 1834 yılında oluşturulmuştur. Ülkemizde hukuk kütüphaneciliği konusundaki ilk STK girişimi 2007 yılında "Türk Hukuk Kütüphanecileri Platformu" adıyla ÜNAK çatısı altında gerçekleşmiştir.

\section{Türk Hukuk Kütüphanecileri Platformu}

İstanbul Bilgi Üniversitesi Kütüphanesinde hukuk koleksiyonu önemli bir yer tutmakta ve ayrı bir kampüste yer almaktadır. Kütüphanede, hukuk alanındaki kütüphane hizmetlerinin etkinliğinin artırıması için çalışmalar yapılmaktadır. Bu çalışmalardan biri de hukuk kütüphanesi hizmeti veren bilgi merkezleriyle birlikte hareket etmek ve örgütlenmektir.

2006 yilında Uluslararası Hukuk Kütüphaneleri Derneği tarafından Rusya'nın St. Petersburg şehrinde 25. Uluslararası Hukuk Kütüphaneleri Konferansı düzenlenmiştir. Bu konferansa katılan 
ülkelerin birçoğu hukuk kütüphaneciliği konusunda STK'na sahip olan ülkelerdir. Bu alanda çok sayıda akademik çalışma ve 25 yıldan bu yana da uluslararası konferanslar yapılmaktadır.

Hukuk kütüphaneciliği sadece üniversite yapısı ile sınırlı değildir, Baro, Anayasa, Sayıştay, Danıştay gibi kurumların kütüphanelerini de kapsamaktadır. Diğer ülkelerdeki örgütlenmelere paralel olarak Türkiye'de geç de olsa hukuk kütüphaneciliği alanında çalışmaların yapılması gerekmektedir. Türkiye'de kütüphanecilik dernekleri 1940’lı yıllardan başlayarak faaliyet göstermektedir. Ancak, hukuk kütüphaneciliğinin dernekleşmesi ayrı bir alan olarak ele alınmamıştır.

Türkiye'de hukuk kütüphaneciliği konusundaki örgütlenme çalışmalarının başlamasına İstanbul Bilgi Üniversitesi Kütüphanesi öncülük etmiştir. İlk olarak hukuk fakültesi olan üniversiteler, kütüphanesi olan baro ve avukatlık büroları tespit edilmiştir. Bu kurumlarda çalışan meslektaşlar konu hakkında bilgilendirilmiş ve 22 Temmuz 2007 tarihinde İstanbul Bilgi Üniversitesinde 7 kurumdan 9 kütüphanecinin katıldığı bir toplantı yapılmıştır. Toplantıda 2006 yılından itibaren İstanbul Bilgi Üniversitesi Kütüphanesinde yapılan çalışmalar konusunda katılımcılar bilgilendirilmiştir. Çeşitli görüşlerin sunulduğu, fikir alışverişlerinin yapıldığı toplantı sonucunda Türk Hukuk Kütüphanecileri Platformu (2007)'nun kurulması kararı alınmış ve yeni bir derneğin kurulması yerine var olan bir dernekle birlikte hareket edilmesi yönünde görüş birliğine varılmıştır. Bu konuda Üniversite ve Araştırma Kütüphanecileri Derneği (ÜNAK) ile görüşmeler yapılmış, 1 Ağustos 2007 tarihinde Platformun ÜNAK'a bağlı bir alt birim olarak oluşumu gerçekleştirilmiştir.

ÜNAK-Türk Hukuk Kütüphanecileri Platformunun vizyonu "uluslararası standartlara uygun bir anlayışla, hukuk alanındaki bilgi kaynaklarının paylaşımını ve erişimini kolaylaştıracak çözümler üretmek ve bu alandaki gelişmelere öncülük etmek" olarak belirlenmiştir. Platformun hedef ve amaçları ise:

- Türkiye'de hukuk alanında hizmet veren kütüphane, dokümantasyon ve bilgi merkezleri arasında işbirliği ve bilgi paylaşımını artırmak, 
- Hukuk kütüphanelerinin etkinlik ve faaliyetlerini geniş kitlelere duyurmak,

- Üniversite Araştırma Kütüphanecileri Derneği (ÜNAK) tarafından düzenlenen yıllık toplantılarda hukuk alanında bildiri sunmak, panel ve çalıştay düzenlemek,

- Türkiye'de hukuk alanında yapılan çalışmaları uluslararası hukuk platformları ve dernekleri ile paylaşmak,

- Hukuk alanında uluslararası standartlara uygun bir veritabanının oluşmasına öncülük etmek,

- Kütüphaneciler ve araştırmacılar için aktif olarak kullanılacak web sayfası oluşturmak,

- Kurumsal arşiv ve açık erişim çalışmalarını desteklemek şeklindedir.

ÜNAK - Türk Hukuk Kütüphanecileri Platformu, kurulumundan hemen sonra web sayfasını yayınlamış, çalışma gruplarını oluşturmuş, panel ve toplantılar düzenlemiştir. Çalışma grupları;

- Açık Erişim Çalışma Grubu,

- Konu Başlıkları Çalışma Grubu,

- Süreli Yayınlar Çalışma Grubu,

- Tanıtım ve lletişim Çalışma Grubu şeklindedir.

Çalışma gruplarının faaliyetlerini düzenli, verimli ve programlı bir şekilde yapmaları için "proje hazırlama formu" oluşturulmuştur. Bu form Avrupa Birliği proje hazırlama formuna uygun olarak tasarlanmıştır (Türk Hukuk Kütüphanecileri, 2008).

ÜNAK- Türk Hukuk Kütüphanecileri Platformu'nun 2007 yılında yaptığı bazı etkinlikler şunlardır:

- 27-29 Eylül 2007 tarihinde Muğla Üniversitesinde ÜNAK tarafından düzenlenen "sayısal dünyada yeni paradigmalar: sınırsız kütüphaneler" adlı konferansta "21. Yüzyılda Hukuk Kütüphaneleri ve İşbirliği" adlı bir panel düzenlenmiştir. Panelde 5 konuşmacı hukuk alanlarında yaptıkları araştırmaları sunmuşlardır. 
- 8 Aralık 2007 tarihinde İstanbul Bilgi Üniversitesinde 11 kütüphanecinin katıldığı bir toplantı yapıımıştır.

- Türk Hukuk Kütüphanecileri Platformunun logosu profesyonel olarak yaptırılmıştır.

- $\quad$ Türk Hukuk Kütüphanecileri Platformu web adresinin Uluslararası Hukuk Kütüphaneleri gibi ilgili web sayfalarına bağlantı verilmesi sağlanmıştır.

- $\quad$ İletişimi kolaylaştırmak ve hızlandırmak için İnternet üzerinde bir tartışma listesi oluşturulmuştur.

- İstanbul Bilgi Üniversitesi ile Hukuk Platformu, 2009 Uluslararası Hukuk Kütüphaneleri Konferansının İstanbul'da yapılmasına öncülük etmektedir. ÜNAK-Türk Hukuk Kütüphanecileri Platformu çalışmalarına hızla devam etmektedir.

\section{Sonuç}

Sivil toplum kuruluşlarının her alanda olduğu gibi kütüphanecilik alanına birçok faydası vardır. Kütüphanecilik alanındaki dernekler ve oluşumlar;

- Mesleki dayanışmayı artırarak sorunların çözülmesine katkı sağlar.

- Kütüphaneciler adına lobi faaliyetleri yapar, kitle iletişim araçlarını kullanarak etkinliklerini duyurur, sosyal girişimciliği özendirir ve toplumsal farkındalığın arttırımasına katkı sağlar.

- Kütüphanecilere, bilgi ve belge yönetimi öğrencilerine yönelik seminer, konferans, eğitim gibi etkinlikler düzenleyerek mesleki ve teknik becerilerin kazanımasına katkı sağlar.

- Mesleki projelerin oluşturulmasında ve dünyadaki gelişmelerin uygulanmasında öncülük edebilir.

*unak-hukuk@yahoogroups.com 
- Kütüphanelerarası ödünç verme, kurumsal arşivleme, açık erişim gibi projelerde hedef üzerinde birlikte çalışmayı kolaylaştıır.

- $\quad$ Çeşitli yayınlar ile mesleki gelişime ve bilim dünyasına katkı sağlar.

- Benzer amaçlı uluslararası kuruluşlara üye olarak üyelerine faydalar sağlar.

- $\quad A B$ sürecinde mesleki işbirliği kapsamında ulusal ve uluslararası düzeyde derneklerle bilgi paylaşımını arttııı, ortak projelerin yapılmasına öncülük eder.

- Kütüphanecilerin sivil toplum kuruluşlarına katıımını teşvik eder, tartışma listeleri oluşturur, bireylerin birbirleriyle ağ oluşturması ve güncel bilginin paylaşıımasına, tartışımasına olanak sağlar. Kütüphanecilik alanında oluşturulacak sivil toplum kuruluşlarının faydaları çoğaltılabilir.

Sonuç olarak, küreselleşmenin de etkisiyle her alanda sivil toplum kuruluşları faaliyetlerini artırmaktadır. Dolayısıyla kütüphaneciler bu gelişim ve değişimi mesleki örgütlerle daha düzenli ve etkin bir şekilde yapabilirler. Bunun için de kütüphanecilik alanında oluşturulacak sivil toplum kuruluşlarının desteklenmesi, etkinliklerine katııımın sağlanması son derece önemlidir.

\section{Kaynakça}

About AALL. (2008). American Association of Law Libraries. 15 Ocak 2008 tarihinde http://www. aallnet.org/about/ adresinden erişildi.

About BIALL. (2008). British and Irish Association of Law Librarians.

15 Ocak 2008 tarihinde http://www.biall.org.uk/Home.asp?id= h1\&h999=a20bdspa6bhida7bhida28bhida2bhida3bdspa19bhida 5bhida8bhida9bdspa adresinden erişildi.

About Jenkins Law Library. (2008). Jenkins Law Library. 15 Ocak 2008 tarihinde http://www.jenkinslaw.org/about/ adresinden erişildi.

About the Law Library. (1996). Library of Congress. 15 Ocak 2008 tarihinde http://www.loc.gov/law/about/ adresinden erişildi. 
About us. (2008). Australian Law Librarians' Association. 15 Ocak 2008 tarihinde http://www.alla.asn.au/index.php?option= com_content\&view=article\&id=55\&ltemid=101 adresinden erişildi.

ANKOS hakkında. (2008). ANKOS. 15 Ocak 2008 tarihinde http://www.ankos.gen.tr/index.php?option=com_content\&task=vie w\&id=12\&ltemid=223 adresinden erişildi.

Diplock, L. J. (1980). Ulusal ve uluslar üstü hukuk sistemlerinin geçişmesi. Ankara Üniversitesi Hukuk Fakültesi Dergisi, 37(1-4), 179-180.

Kallendorf, C. E. Jr. (2008). The History of the Cincinnati Law Library Association. 15 Ocak 2008 tarihinde http://www.hamiltonco.org/cinlawlib/about/history.html adresinden erişildi.

Sivil toplum kuruluşu. (2008). Vikipedi: Özgür ansiklopedi. 15 Ocak 2008 tarihinde http://tr.wikipedia.org/ wiki/Sivil_toplum_kurulu\%C5\%9Fu adresinden erişildi.

Torun, O. ve Özyurt, S. (2003). Okul Kütüphanecileri İstanbul Grubu tanıtım broşürü. İstanbul.

Türk Hukuk Kütüphanecileri Platformu. (2007) 15 Ocak 2008 tarihinde http://thk.bilgi.edu.tr/ adresinden erişildi.

Türk Kütüphaneciler Derneği (TKD). (2008). 15 Ocak 2008 tarihinde http://www.kutuphaneci.org.tr adresinden erişildi.

Üniversite ve Araştırma Kütüphanecileri Derneği. (ÜNAK). (2008). 15 Ocak 2008 tarihinde http://www.unak.org.tr adresinden erişildi.

Yaratıcı Kütüphane Girişimleri Tanıtım Grubu (ILIPG). (2008). 15 Ocak 2008 tarihinde http://www.library.itu.edu.tr/lilipg/index_tr.html adresinden erişildi. 